\title{
Em busca da casa perdida: a cabana primiti- va segundo Laugier e Semper
}

\author{
In search of the lost house: the primitive hut according to Laugier and \\ Semper
}

Alice de Oliveira Viana*

${ }^{*}$ Doutora em Arquitetura e Urbanismo pela Faculdade de Arquitetura e Urbanismo da Universidade de São Paulo (FAUUSP). Professora da Universidade do Estado de Santa Catarina (UDESC). ORCID: $\quad 0000-0002-7328-$

9795

\section{Resumo}

O presente trabalho pretende cotejar duas investigações teóricas sobre a casa primordial, que renovaram as discussões sobre o tema em Arquitetura: a de Marc-Antoine Laugier e a de Gottfried Semper. Em ambos, a habitação primitiva é uma cabana, produto humano, pensado e fabricado pelos homens e, com isso, sujeito à reflexão teórica. Insatisfeitos com a condição contemporânea da Arquitetura, avaliando o momento como uma época de desvirtuamento na prática arquitetônica, Laugier e Semper, cada um em sua época, usaram essa casa imaginada como estratégia discursiva para propor modificações em seu meio. Nesses autores, a imagem da cabana e o discurso sobre ela serviram, em grande medida, como um expediente para tempos percebidos como de crise.

Palavras-chave: Arquitetura. Habitação primitiva. Teoria da arquitetura.

\section{Abstract}

This paper aims to compare two theoretical investigations on the primordial house that renewed the discussions on the subject in the architectural field: that of Marc-Antoine Laugier and that of Gottfried Semper. In both, the primitive dwelling is a hut, a human product, designed and manufactured by men and, therefore, subject to theoretical reflection. Dissatisfied with the contemporary condition of Architecture, evaluating the moment as a time of distortion in architectural practice, Laugier and Semper, each in their own time, used this imagined house as a discursive strategy to propose changes in their field. In these authors, the image of the hut and the discourse about it served, to a great extent, as an expedient for times of crisis.

Keywords: Architecture. Primitive dwelling. Architectural theory.

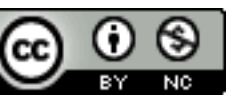

Recebido: 22/04/2020

Aceito: $22 / 06 / 2020$

https://doi.org/10.37916/arq.urb.v28i.423 


\section{Introdução}

A busca da casa dos primeiros habitantes do planeta, tema que Joseph Rykwert investiga em A casa de Adão no Paraíso (2003), foi uma constante inquietação de muitos estudiosos, praticantes e amantes da Arquitetura. Desde os princípios da teoria da Arquitetura na tradição ocidental, conjecturar a primeira morada foi atitude recorrente em tratados e escritos teóricos. Para muitos, a suposta proximidade com as origens consubstanciaria certa verdade originária, certa incorruptibilidade que guardaria os princípios da própria disciplina arquitetônica. Buscá-la, ou melhor, imaginar essa casa, foi necessário toda vez que, na história da Arquitetura, foi preciso perscrutar os fundamentos da disciplina.

O presente trabalho pretende pôr em destaque duas investigações sobre a casa primordial: a do sacerdote jesuíta Marc-Antoine Laugier (1713 1769) e a do arquiteto e teórico Gottfried Semper (1803-1879). Seus escritos deram continuidade a uma prática discursiva iniciada com o tratado de
Vitrúvio e retomada por seguidores modernos deste último. Nas reflexões de Laugier e Semper, distantes em um intervalo de cem anos, a primeira casa é a habitação dos primeiros indivíduos, conquistada mediante a construção de uma cabana. Ou seja, trata-se de um produto humano, algo pensado e fabricado pelos primeiros habitantes, que usaram suas habilidades para atender a suas diferentes necessidades. E justamente por ser um produto do homem, talvez fosse possível deduzir premissas subjacentes à prática.

Ambos estudiosos, admiradores e envolvidos, cada um a seu modo, com a Arquitetura, e insatisfeitos com a condição contemporânea deste campo do saber e da prática construtiva, usaram essa casa imaginada como estratégia discursiva para propor modificações em seu meio. Entendendo o momento como uma época de desvirtuamento na prática arquitetônica, tanto o sacerdote quanto o arquiteto tinham no discurso da casa uma espécie de reação à arquitetura que estava sendo praticada em sua épo- 
ca respectivamente, as experimentações do rococó e do barroco tardio, de meados do século XVIII, e do ecletismo de meados da centúria seguinte, e, por isso, endereçaram sua mensagem aos arquitetos e àqueles de algum modo envolvidos com arquitetura e construção.

\section{A casa vitruviana e seus herdeiros}

O tratado de Vitrúvio, datado do século I a.C, é o texto mais antigo que até nós chegou da chamada Antiguidade Clássica e, em grande medida, consiste na fonte de boa parte das narrativas sobre a casa primordial na tradição ocidental. No capítulo primeiro do segundo livro do De Architectura Libri Decem (VITRÚVIO, 2007), o surgimento da habitação humana é associado à descoberta do fogo. Em um relato mítico sobre as origens, o autor sustenta que foi a constatação da vantagem da reunião dos corpos ao redor do calor do fogo que levou à reunião entre os homens, ao surgimento da vida em sociedade e da linguagem falada. A vida sedentária daí decorrente teria acarretado a necessidade de uma proteção, a qual foi resolvida não com a ocupação de uma caverna ou com a exploração de um refúgio natural, mas com a construção coletiva de um abrigo para morar.

Na célebre passagem, Vitrúvio destaca a importância do ingegno humano, mediante a observação e imitação da natureza e o contínuo exercício dos indivíduos no aperfeiçoamento de seus abrigos. Se inicialmente esses abrigos teriam sido feitos como os ninhos das andorinhas ou cavernas sob os montes, com o constante refinamento dos sistemas de construção e o aprimoramento do juízo humano, deixaram de ter o aspecto de simples cabanas, construções instáveis e precárias, e tornaram-se casas, "com alicerces, construídas com paredes de tijolo ou de pedra e cobertas por madeira e telha". Seus construtores, em seguida, teriam passado "dos juízos vagos e incertos, à certa racionalidade das comensurabilidades, através das observações das obras" (2007, p.116).

Notam-se, nesse importante trecho, premissas fundamentais a circunscrever o domínio da disciplina a transformação do abrigo precário original em uma casa propõe diferenciar a esfera da architectura daquela da aedificatio. A primeira distinguindo-se pela busca da comensurabilidade, princípio da beleza no De Architectura, e que, no contexto do tratado antigo, afirmaria a arquitetura como uma arte liberal, distinta dos ofícios mecânicos, a envolver o juízo e a reflexão humana. Marca igualmente essa distinção a transformação de um sistema construtivo precário para um mais durável, que na narrativa vitruviana delineia-se como a petrificação dos elementos estruturais originais em madeira, teoria que o autor legitima com o princípio da imitação e que no tratado adquire relevância no exame dos templos religiosos.

No Renascimento, com a redescoberta e revalorização dos escritos de Vitrúvio, a narrativa sobre as origens da Arquitetura adquire nova importância como 
1. Para maior aprofundamento acerca das especulações sobre a cabana primitiva no Renascimento, conferir ANDRADE (2017).

2. As tentativas de tradução, comentários e referências ao autor latino se apresentavam com muitas dificuldades, impostas à tradução de uma escrita que, na acepção crítica de Alberti, não era culta, "de modo que os latinos diriam que quis parecer grego e os gregos, latino", eram muitas (ALBERTI, 2012, p. 213).

3. Muitos procuraram adaptar tal narrativa àquela contida nas sagradas escrituras.

4. Respectivamente, "Di Lucio Vitruvio Pollione De architectura libri dece: traducti de latino in vulgare, affigurati, comentati" e "Trattato di architettura".

usjt • arq.urb • número 28 | maio - agosto de 2020 tema especulativo. No primeiro tratado arquitetônico da era moderna, o De Re Aedificatoria (escrito entre 1443 e 1452), destinado a emular o texto de seu antecessor, o tema não deixa de comparecer. Seu autor, o humanista florentino Leon Battista Alberti, que tomou conhecimento dos escritos do arquiteto romano e teceu sobre eles comentários e críticas, não investe em uma narrativa mítica, consoante ao que fez Vitrúvio, mas apresenta notas esparsas que mantêm a fundamentação principal da construção de um abrigo nas necessidades humanas e na atuação coletiva dos indivíduos.

No discurso de Alberti, não foi o fogo o responsável por reunir os indivíduos, mas antes a necessidade de proteção contra as intempéries, que levou à criação de tetos e paredes. Para o erudito, a arte surgiu do acaso e, assim como no autor do De Architectura, progrediu com a observação, a imitação, a prática e, sobretudo, o raciocínio, faculdade mental que, para Alberti, distinguiria a atividade do arquiteto daquela associada aos ofícios mecânicos (ALBERTI, 2012). Do escrito de Alberti, averíguase que, também no Renascimento, a distinção entre uma cabana primitiva, de materiais precários e provisórios, e uma habitação mais durável, perene fundada sobre o alicerce da razão, da imitação e de preceitos racionais, fixa os principais parâmetros de reconhecimento e distinção da chamada arte edificatória.
O tratado de Alberti, dedicado aos temas e preceitos que regem a arte da edificação, pouco se detém na especulação sobre as origens da disciplina. De modo contrário, nos tradutores e comentadores de Vitrúvio dos séculos XV e XVI, vê-se surgir uma grande fortuna da ideia da cabana primitiva ${ }^{1}$. Estando já estabelecida a autoridade de Vitrúvio, sobretudo após a contribuição e mediação de Alberti, interpretar o texto do arquiteto romano - e nele a passagem sobre as origens da Arquitetura -, do qual as imagens foram perdidas e a escrita em si se mostrava deveras obscura, era estratégia para o estabelecimento de um preceituário arquitetônico e para a dignificação da Arquitetura como uma arte liberal, não mais um ofício mecânico, como havia sido durante a Idade Média ${ }^{2}$.

Grande parte dos interlocutores do texto vitruviano, haja vista as idiossincrasias de cada um, comentou e ilustrou sua narrativa sobre as origens ${ }^{3}$, narrando a descoberta do fogo, bem como a construção coletiva dos primeiros abrigos e seu aperfeiçoamento em algo mais durável. Tais avanços construtivos costumeiramente foram fundamentados não só no aprimoramento da prática, mas também no uso de habilidades mentais do homem. Desta literatura, pode-se citar, por exemplo, a primeira tradução comentada e ilustrada do tratado de Vitrúvio, de autoria de Cesare Cesariano e que surge em 1521, e também o tratado de Antonio Averlino, dito Filarete, textos cujas ilustrações sobre este tema fizeram parte da rica iconografia renascentista ${ }^{4}$ (Figuras 1 e 2). 


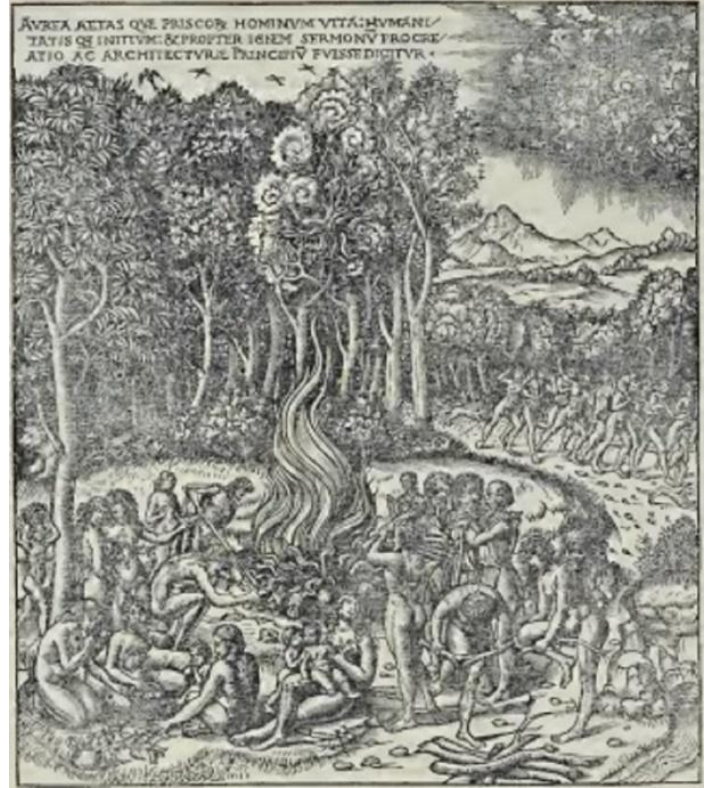

Figura 1 - A descoberta do fogo. Cesare Cesariano 1521. Fonte: CESARIANO, 1521. Domínio público.

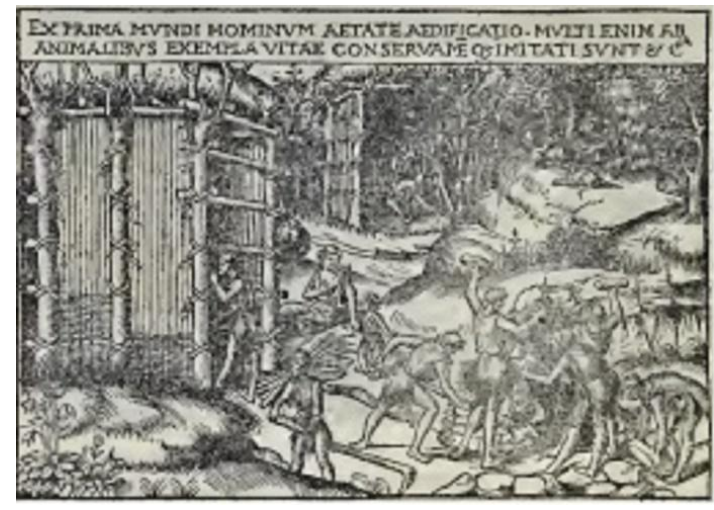

Figura 2 - A construção da cabana primitiva. Cesare Cesariano, 1521. Fonte: CESARIANO, 1521. Domínio público.

usjt • arq.urb • número 28 | maio - agosto de 2020

víduos.

Nessa literatura renascentista, mesmo em alguns escritos do século XVII - como no "Les Dix Livres d'Architecture de Vitruve", traduzido e "corrigido" pelo arquiteto Claude Perrault (1613-1688), do ano de 1673 -, a narrativa sobre as origens da Arquitetura e a especulação sobre uma cabana primitiva apresentam-se como um dos muitos esforços da exegese vitruviana, das tentativas de compreender, ou mesmo revisar, o texto antigo, não apresentando, no discurso de seus autores, mais do que uma ligação superficial com os princípios da disciplina, ou seja, seu propósito distanciava-se da tentativa de estabelecer novos fundamentos para a Arquitetura (RYKWERT, 2003). Situação diversa se instaurará no chamado século das Luzes, em que o exame das origens adquire novo valor no movimento geral de revisão da tradição e de seus pressupostos.

\section{La petite cabane rustique de Marc-Antoine Laugier}

Foi no século XVIII que o tema das origens da Arquitetura e a investigação sobre uma primeira casa adquiriram uma importância considerável, em grande medida como parte do interesse iluminista pelas causas primeiras e pela "certeza" das origens. Naquele contexto, a busca pelas origens integrava as estratégias de revisão dos pressupostos tidos como dados pela tradição e contribuía na construção de novos princípios explicativos acerca de costumes, hábitos e práticas culturais dos indi-
No campo teórico da Arquitetura, essa atitude crítica com relação à tradição é observada nos escritos de Marc-Antoine Laugier, caracterizado por Emil Kaufmann (1952, p.448) como um "típico representante do lluminismo", e cujos escritos "exemplificam as tendências arquitetônicas de meados do século XVIII". Em seu Essai sur l'Architecture, surgido em meados do século, consoante Rykwert (2003, p.41), "as origens desfrutavam de uma autoridade única" e a noção de uma cabana primitiva adquire uma "prioridade absoluta" (2003, p.35), como padrão de excelência a guiar a criação e também o julgamento das obras arquitetônicas.

A primeira edição do Essai apareceu em 1753, publicada de forma anônima pelo autor, e, devido ao sucesso obtido, foi logo seguida de uma segunda edição, dois anos depois, com ampliações e ilustrações, desta vez com a identificação da autoria. Trata-se de um tratado que, como colocam Vázquez Ramos e Tourinho (2015, p.173), se por um lado segue a tradição dos tratados franceses do século XVII, como os de Jean-Louis de Cordemoy (1655-1714) e do mencionado Claude Perrault, por outro questiona criticamente a tradição, sobretudo a "legitimidade impositiva dos exemplos do passado" - uma vez que a cópia dos modelos antigos se mostrava como prática comum da Academia Francesa à época. 
No contexto amplo, o Essai reage às extravagâncias e arbitrariedades formais e decorativas do rococó e do barroco tardio, que para o autor estavam distorcendo as formas simples e puras da Arquitetura e desvirtuando-a de seus sólidos princípios. Tais princípios, para ele, estavam fundados em leis fixas e imutáveis que se encontravam na "simples natureza" e que eram de aprovação geral por serem sancionadas pela razão, ao invés do mero gosto ou costume (1755). A arte, para o sacerdote, deve seu surgimento à imitação desta simples natureza e de seus procedimentos; evitam-se todos os erros e desvios acercando-se desta simplicidade e pureza originárias - tal é a premissa que Laugier procura firmar logo no início de seu tratado, ao narrar como supostamente a Arquitetura surgiu (1755).

No capítulo inicial do Essai, não casualmente intitulado "Princípios Gerais da Arquitetura", o autor apresenta uma narrativa sobre o homem primitivo vivendo em seu ambiente natural e "sem outro guia que o instinto natural de suas necessidades" (1755, p.10). Assim como ocorre com a ideia do nobre selvagem descrito por um contemporâneo de Laugier, o filósofo Jean-Jacques Rousseau (1712-1778), o primitivo de Laugier e a cultura primitiva por ele imaginada, de um modo geral, não consistem, como lembra Alan Colquhoun (2004, p.46), na "descoberta empírica de um verdadeiro vernáculo". Ou seja, não se trata de uma concepção empírica do primitivo, resultada da apreensão de dados, mas sim de uma abordagem especulativa e apriorística; trata-se de "uma hipótese fundada no que logicamente deve ter ocorrido, associando o lógico ao cronológico" (COLQUHOUN, 2004, p.46).

Não obstante tal proximidade entre o selvagem do filósofo e aquele do sacerdote, Laugier, diversamente de Rousseau, não aborda a vida primitiva de um ponto de vista moral, não intenciona descrever um indivíduo em meio à natureza confortado com a satisfação de seus instintos e suas necessidades, tampouco pretende incentivar os contemporâneos a retornar a essa condição "natural" (RYKWERT, 2003). Pelo contrário, a narrativa das origens surge em seu tratado mais como uma crítica à situação contemporânea e uma referência para a elaboração de princípios válidos para a prática da boa Arquitetura.

Diversamente ao observado nos escritos de Vitrúvio, esse capítulo inicial do Essai não vincula as origens à descoberta do fogo, mas igualmente descreve um indivíduo confrontado com a necessidade de guardar-se das intempéries e dos fenômenos da natureza. Tal primitivo busca, sem sucesso, uma proteção natural. Após tentativas de ocupação de cavernas e abrigos naturais, nos quais variadas inconveniências não the davam a proteção e satisfação desejadas, decide ele mesmo construir um abrigo. Recolhe quatro fortes troncos encontrados no solo, ergue-os perpendicularmente e os dispõe em uma espécie de quadrado. Sobre o topo ele coloca 


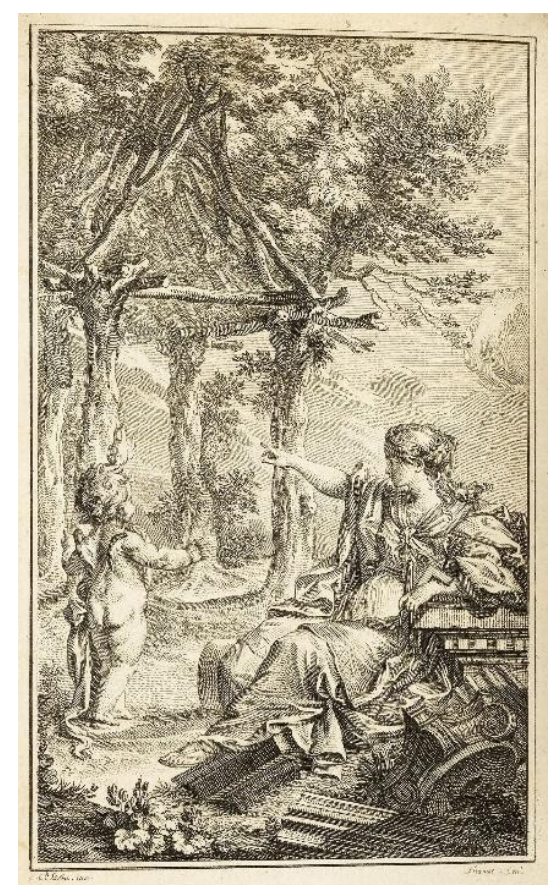

Figura 3 - A cabana primitiva segundo Laugier, 1755. Fonte: LAUGIER, 1755. Domínio público. mais quatro troncos horizontalmente e em seguida ergue um telhado, formado de peças inclinadas e reunidas em um ponto e coberto com folhas, de modo a se proteger tanto do sol quanto da chuva (LAUGIER, 1755).

Assim o religioso descreve a origem da Arquitetura. A "petite cabane rustique", tornada célebre pela gravura de Charles Eisen (1720-1778) elaborada para a segunda edição do Essai (Figura 3), tratava-se da resolução natural e instintiva das necessidades desse homem primitivo e tinha cada uma de suas partes associada àquilo que ele entendia como os elementos essenciais da composição da Arquitetura, as quais deveriam servir de modelo para toda criação: colunas, entablamento e frontão (LAUGIER, 1755).

O modelo originário de Laugier é concebido com base na imitação de elementos essenciais derivados da natureza, em que cada uma das partes atenderia a uma razão natural. É imitando este modelo que se alcançavam todas as virtudes em Arquitetura:

a pequena cabana rústica que eu acabo de descrever é o modelo sobre o qual nós imaginamos todas as magnificências em Arquitetura, é se aproximando da execução da simplicidade deste primeiro modelo que se evitam todos os defeitos essenciais, que se alcançam as reais perfeições (LAUGIER, 1755, pp.12-13).

No desenvolvimento histórico da Arquitetura, os elementos compositivos e a forma final do abrigo primitivo teriam sido plenamente desenvolvidos pelos gregos, os quais, mediante reflexão e aprimoramento, teriam levado o modelo da cabana à perfeição artística no tipo do templo períptero. Se por um lado, esse ponto de vista de Laugier dá continuidade à crença tradicional, derivada de Vitrúvio e perpetuada nos textos da tradição renascentista, de que o templo grego, em pedra polida, teria derivado sua morfologia e relações métricas diretamente de um primeiro abrigo construído em matéria lígnea, por outro, coloca-se em confronto com essa mesma herança ao assumir a primordialidade da arquitetura helênica. Tal postura, de outra forma, o coloca em consonância às reflexões de Johann Joachim Winckelmann, seu contemporâneo. Para Winckelmann (1955), a arquitetura helênica seria a origem de toda arquitetura ocidental e de todas as invenções artísticas, as quais teriam sido em seguida copiadas pelos romanos e distorcidas na época moderna. Consoante, esclarece Azevedo (2009, p.53, grifo do autor), no Essai,

especula-se o trilhamento regressivo de uma vereda pela qual, remontando-se aos romanos, e, destes, aos helênicos e daí até a mais remota ancestralidade, à medida que mais se retroage à pureza incorrupta das origens, mais se acerca do verdadeiro, do natural. A construção originária em rústica madeira - mais tarde perenizada em polido mármore e ajustada ao cânone da medida humana - fixa, imutável, a forma (eidós) pela qual se consubstanciaria o arquétipo imaculado da verdadeira Arquitetura. 
5. Alan Colquhoun (2004, p.47) define o classicismo de Laugier como um "classicismo vernáculo", no sentido de "um processo pelo qual o classicismo, nos termos de sua própria teoria de linguagem, recria suas próprias origens", buscando as fontes puras e incorruptas da arquitetura clássica.
Apesar de advogar que tal verdadeira Arquitetura era encontrada na reunião das partes essenciais, estritamente indispensáveis - coluna, entablamento e frontão -, estando aí toda sua beleza, Laugier (1755) não deixa de admitir a possibilidade da existência de partes que ele indica como necessárias, as quais seriam toleráveis em virtude de uma necessidade de uso, como, por exemplo, portas, janelas e vedações. Tais elementos ele aponta como licenças, termo que, como lembra Rykwert (2003, p.41), "na antiga teoria da arquitetura foi aplicado em relação aos caracteres ornamentais que não eram consagrados pela antiguidade", estando associado, no período do Renascimento, mais ao capriccio, àquilo que foge à norma, do que à razão.

Se nas partes introduzidas pela necessidade do uso encontram-se as licenças aceitáveis, naquelas acrescentadas por puro capricho e arbitrariedade estaria tudo aquilo que é inaceitável, todos os defeitos e falhas da Arquitetura (LAUGIER, 1755) condenados pelo sacerdote, tal como arcos, áticos, pilastras, pedestais, nichos, frontões interrompidos ou curvos, entre outros elementos bastante explorados nos monumentos barrocos, que não se encontravam na cabana primeira e, deste modo, cujo emprego não se justificava.

Em seu discurso, Laugier parte do próprio edifício clássico para confrontá-lo e restabelecê-lo sobre novos alicerces ${ }^{5}$.
Nesse sentido, os elementos essenciais da Arquitetura, que compuseram a cabana tal qual construída pelo primitivo e que seriam as partes da edificação, são para ele as próprias ordens clássicas. Destas, ele reconhece apenas três - dórica, jônica e coríntia -, mas, atento à relevância assumida pelo papel do gosto na época, exorta os arquitetos contemporâneos a inventarem novas, desde que suas partes atendam estritamente à conveniência à utilidade, tal como fora na gênese. Frontões, por exemplo, deveriam ser triangulares e localizarem-se acima do entablamento, na largura das edificações, nunca em sua parte longitudinal. Entablamentos deveriam estar sobre as colunas e serem retilíneos, sem angulações e relevos. E colunas, aprumadas, preferencialmente isoladas, sem pedestal e cilíndricas - "porque a natureza não faz nada quadrado" (LAUGIER, 1755, p.16). Dessas três partes, a coluna é aquela a que ele dedica maior atenção em seu texto. Tendo em vista que paredes seriam apenas toleráveis como vedação e proteção, e considerando a reiterada ênfase que o autor concede à unidade formal das ordens clássicas, a coluna é elemento substancial em seu discurso, tornando-se "mais que o componente estrutural da construção, o epítome estruturante de toda Arquitetura" (AZEVEDO, 2009, pp.5455).

O impacto das propostas de Laugier fez-se sentir logo após a publicação do Essai, o qual foi "aclamado e avidamente lido por toda a Europa" e recebido por muitos como um "panfleto revolucionário" (MID- 
6. Sobre as reflexões de Quatremère de Quincy acerca da cabana primitiva, conferir PEREIRA (2010).

7. Semper foi professor em instituições de ensino em Dresden, Londres e Zurique. Para maior aprofundamento de sua trajetória profissional, conferir MALLGRAVE (1996).

8. Em 1849, Semper teve que abandonar os territórios de língua alemã por conta de seu envolvimento na insurgência contra a coroa de Dresden, durante as revoluções que ocorreram nas principais cidades europeias entre 1848-9.

usjt • arq.urb • número 28 | maio - agosto de 2020
DLETON; WATKIN, 1987, p.20). A partir de sua divulgação, muitas arquiteturas procuraram ilustrar suas ideias, as quais, em grande medida, se tornaram "a ordenação arquitetônica do lluminismo" (RYKWERT, 2015, p.35). De não menor repercussão foram suas propostas no campo da teoria da Arquitetura. O sucesso da obra fez do sacerdote jesuíta "um dos pensadores mais lidos e respeitados pelos arquitetos mais avançados de sua época e do século XIX" (VÁZQUEZ RAMOS; TOURI$\mathrm{NHO}, 2015$, p.171) e contribuiu para formar discípulos em vários países europeus - um dos mais célebres, Quatremère de Quincy, secretário perpétuo da Academia de Beaux-Arts ${ }^{6}$ - que sustentaram o ideal da imitação clássica da cabana em suas orientações teóricas ao menos até as primeiras décadas do século seguinte.

Em meados do século XIX, se a perspectiva idealista de Laugier perde vigor, tendo em vista sobretudo os aportes do historicismo alemão, a postura de retorno às origens, de busca de uma casa ancestral da Arquitetura, como meio de ancorar propostas teóricas, ainda vai encontrar novas reformulações no pensamento de um dos mais importantes estudiosos da Arquitetura, o arquiteto e teórico hamburguês Gottfried Semper, cujo discurso procurou contrapor as formulações do sacerdote francês.

\section{Gottfried Semper e a cabana caribenha}

De modo distinto ao do autor do Essai, Gottfried Semper era arquiteto, tendo em muito se envolvido com a parte prática da Arquitetura, atividade que sempre que possível foi conciliada com suas férteis investigações teóricas e com o ensino ${ }^{7}$. Em seus escritos, a especulação sobre uma casa primordial aparece pela primeira vez em sua segunda obra publicada, Die vier Elemente der Baukunst [Os quatro elementos da Arquitetura], e segue como fio condutor de sua teoria até a publicação da opus magnum, Der Stil [O Estilo], obra de maturidade, publicada em dois volumes (1860 e 1863), e na qual ele procura apresentar, de modo unitário, seu pensamento teórico.

Publicada em 1851, no começo de seus anos de exílio, Die vier Elemente é uma obra organizada em duas partes ${ }^{8}$. A primeira parte contém suas ideias sobre a policromia clássica - tema que agitou as principais cidades europeias nas primeiras décadas do século XIX - e é delineada como uma espécie de resposta do autor às assertivas de um de seus grandes adversários, o historiador Franz Theodor Kugler (1808-1858), defensor da tese winckelmaniana da brancura da arquitetura clássica, sobretudo aquela da Acrópole ateniense, proposição que Semper veementemente refutou e procurou contestar ao longo de toda sua carreira. A segunda parte, que se inicia no quinto capítulo e que ele procura incorporar teoricamente à primeira, apresenta ao pú- 
blico, pela primeira vez, sua teoria da Arquitetura, baseada em suas reflexões sobre a habitação primitiva, a casa dos primeiros habitantes.

A cultura primitiva ali delineada é diversa daquela que o sacerdote francês traçou no Essai aproximadamente cem anos antes. A teorização do autor de Die vier Elemente sustenta-se sobre os estudos contemporâneos das culturas primitivas levados a cabo por campos científicos então emergentes, como a etnologia e a história da cultura. Deste modo, sua cabana não é um simples produto da imaginação, tampouco é uma elaboração apriorística; pelo contrário, ela funda-se sobre bases investigativas reais, as quais serviam para traçar paralelos conceituais com o passado remoto. Como esclarece Rykwert (2015, p.36), Semper parte dos "primitivos 'modernos"', cujas práticas e cultura material na época serviam de analogia para os primitivos antigos, já que as cabanas e o modo de vida destes últimos não poderiam ser reconstituídos.

Dentre os estudos sobre as culturas primitivas, uma das prováveis referências de Semper foram os escritos etnológicos elaborados por Gustav Klemm, com os quais, segundo Mallgrave (1985), o arquiteto provavelmente teve contato durante os anos que morou e trabalhou na cidade de Dresden. Klemm é o responsável pela elaboração de uma vasta obra literária, a Allgemeine Culturgeschichte der Menschheit (1843-1852), apresentada em dez volumes, e que tinha a pretensão de ser uma "história cultural da humanidade", abarcando variados fatos antropológicos, tais como os costumes, crenças, hábitos, artefatos, habilidades, práticas religiosas, vida doméstica e pública, entre outros aspectos culturais dos homens, examinados desde os primórdios, ou seja, desde as culturas primitivas.

No quarto volume da sua Culturgeschichte, Klemm (1845, p.289) descreve as habitações dos primeiros indivíduos como "cabanas quadrangulares com um telhado de duas águas pendentes", elevadas do solo mediante uma plataforma em pedra e cujas "paredes laterais consistem de materiais trançados". No centro da cabana, um local para o fogo, no qual "dia e noite uma pequena chama é mantida ininterruptamente". Tal descrição é muito próxima à que Semper apresenta no quinto capítulo de seu Die vier Elemente. São estas quatro partes da cabana descrita por Klemm que irão compor os quatro elementos da habitação primitiva de Semper: um telhado de duas águas, uma plataforma elevada, divisórias verticais e um local para o fogo.

Essas partes não assumem igual relevância no discurso do autor; de todas, uma importância particular é conferida ao local do fogo: "é o primeiro e mais importante, o elemento moral da arquitetura" (SEMPER, 1851, p.55), em torno do qual surgem, sobretudo com o propósito de proteção contra ataques de inimigos e intempéries, os outros três elementos. Tal importância atribuída ao fogo é assim justificada 
por Semper (1851, p.55):

ao redor do fogo os primeiros grupos se reuniram; nele as primeiras alianças se teceram; nele os primeiros rudes conceitos religiosos foram formulados nos usos culturais de um culto. Por todas as fases de desenvolvimento da sociedade o fogo formou o ponto sagrado ao redor do qual o todo tomava ordem e forma.

O local do fogo é o elemento que não somente aquece e serve para o preparo de alimentos, mas, sobretudo, reúne os indivíduos tendo em vista propósitos culturais diversos - mormente religiosos. É o responsável pelo surgimento da vida em sociedade e pela condução a uma vida civilizada, premissas que, se não se observam explicitamente no tratado de Laugier, aproximam Semper do pensamento vitruviano, na medida em que ambos conferem um papel nobre à chamada arte edificatória, ao coincidirem a origem da Arquitetura com a origem da vida em sociedade.

Não obstante essa afinidade à tradição vitruviana, a teorização semperiana caracteriza-se mais pelo distanciamento, tanto das premissas do arquiteto romano, quanto, sobretudo, de suas interpretações e revisões posteriores, como aquela do sacerdote francês. Uma das principais divergências é que a casa ancestral concebida por Semper não pretendia ser um protótipo formal a ser perseguido e reproduzido. Ao se referir à habitação primitiva como constituída por quatro partes, o autor tinha em mente não necessariamente partes ou formas materiais; o que ele delineia como "elementos" é antes pensado como "motivos originários" da Arquitetura [Urmotiven], ou seja, ideias arquitetônicas originárias, princípios criativos e simbólicos que permitem variações e interpretações diversas dependendo das particularidades geográficas, climáticas e culturais de cada sociedade ou grupo cultural. Trata-se de forças criativas que correspondem a gestos ou procedimentos de fabricação artística - por exemplo, elevar do solo, no caso da plataforma, ou delimitar, encerrar, no caso da divisória. Essas forças, reificadas, resultam nas quatro configurações arquitetônicas acima elencadas: o telhado, a plataforma, as divisórias e um local para o fogo. Dependendo das variáveis, é possível que não exista um dos elementos, ou que haja maior desenvolvimento de outro.

Outra notável divergência com a cabana neoclássica apresenta-se no fato de Semper ter rejeitado uma origem lígnea a sua casa, bem como sua posterior transformação integral em pedra. Para o teórico, uma cabana de madeira não poderia ser a origem da Arquitetura, tampouco o princípio - no duplo sentido que este termo acolhe - do templo grego em pedra. Herdeiro de uma tradição de pensamento que desde princípios do século XIX vinha considerando a importância da abordagem dos aspectos materiais na Arquitetura, Semper concebeu que para cada parte formal de sua cabana haveria um material e um ofício específicos, mais adequados ao 
9. Uma das referências de Semper foram os escritos do historiador da arte Karl Friedrich von Rumohr (1785-1843), que advogava pela consideração de fatores como necessidade, propósito e material na apreciação e fabricação de obras. Cf. RUMOHR (vol. 1, 1827).

10. Para maior aprofundamento desse assunto, conferir VEN (1978). propósito construtivo; ou seja, os motivos foram por ele associados às operações técnicas das artes aplicadas: ao local do fogo foi associada a cerâmica e o ofício com argila; à divisória vertical, fibras têxteis e o trabalho de trançados ou tecelagem; à plataforma elevada foi associada a pedra e o ofício da estereotomia ou trabalho com alvenaria de pedras; ao telhado vinculou-se a madeira e a carpintaria ${ }^{9}$.

Igualmente atestando a refutação do discurso neoclássico sobre as origens da Arquitetura encontrase o fato de o teórico também abdicar de atribuir à coluna o papel de protagonista em sua cabana, contrariamente à posição do sacerdote francês. Compondo uma unidade junto ao telhado de duas águas, na qual ela assume o propósito de sustentação, nas especulações semperianas a coluna perde o posto para a parede divisória. Esta, que no Essai consistia em um dos elementos toleráveis do rigorismo de Laugier, em Semper, maleável, móvel e formada pela textura ornamental do entrelaçamento de fibras têxteis, seria o elemento definidor da Arquitetura, pois, segundo ele, estaria associada à criação do espaço. Para Semper, a essência da Arquitetura estaria no encerramento de um espaço ${ }^{10}$. Tal ideia, apresentada no Die vier Elemente e desenvolvida posteriormente no Der Stil, é neste último assim colocada: "a parede é aquele elemento arquitetônico que formalmente evoca e identifica externamente aos olhos o espaço cercado como tal, por assim dizer, absoluto e sem refe- rência a conceitos secundários" (SEMPER, vol.1, 1860 , p.227). Essa premissa, que em grande medida coloca o autor como um dos precursores na associação moderna entre arquitetura e espaço, vai ao encontro de sua perspectiva antropológica, pois a parede, ao separar um dentro e um fora, separa a vida interna da externa, ou seja, ela define o espaço ocupado, o espaço habitado. Logo, a parede semperiana não consiste em uma licença, em um expediente tolerável em virtude dos usos e das necessidades humanas, como se observava na petite cabane rustique; sem ela, não há vida social.

Com a proposta da cabana semperiana, cuja concepção, em princípios da década de 1850, Semper encontrou uma notável confirmação no exemplar de uma cabana caribenha (figura 4) exposta na grande exposição industrial londrina de 1851, Semper "demoliu o protótipo da concepção clássica da Arquitetura, a cabana vitruviana, e colocou em seu lugar o conceito pluralista dos quatro elementos (fogo, cerca, telhado, plataforma) como tipos originários da Arquitetura" (GEORGIADIS, 1992, p.61). Mas, assim como se nota no discurso clássico, a cabana de Semper não seria considerada Arquitetura, apenas seu estágio material. Para o teórico, a transformação para materiais mais duráveis não somente não era fenômeno exclusivo grego, como consistia em um processo que, superando as necessidades materiais, atendia também a exigências de ordem simbólica. Para Semper (vol.1, 1860), e também para seu predecessor francês, a verdadeira arquite 

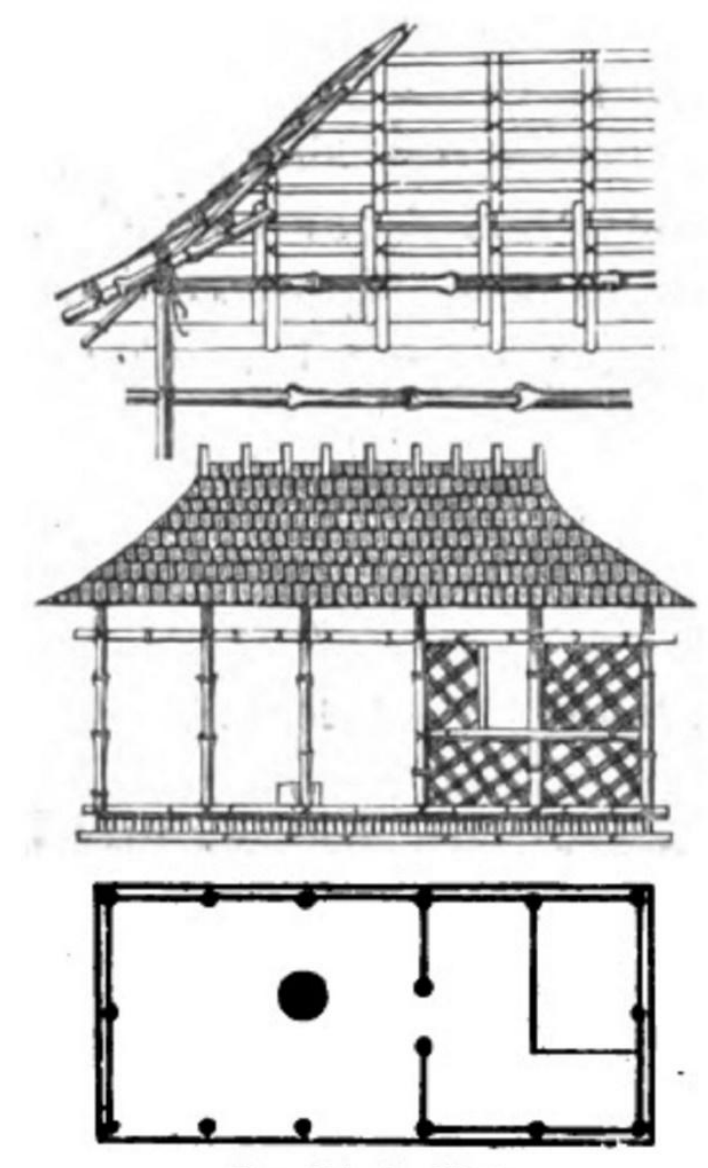

Karaibische Hatte.

Figura 4 - A cabana caribenha encontrada por Semper, 1860. Fonte: SEMPER, 1863. Domínio público.

usjt • arq.urb • número 28 | maio - agosto de 2020 tura é e deve ser da ordem do monumento.

\section{Considerações Finais}

Haja vista as particularidades teóricas e discursivas de cada autor, ambos procuraram resoluções para os dilemas que observavam em sua época mediante o retorno às origens da Arquitetura. De certo modo, não somente os discursos, mas também as imagens de habitação primitiva aos autores associadas têm contribuições a sugerir acerca disso. $\mathrm{Na}$ gravura de Charles Eisen (conferir figura 3), a figura feminina, alegoria da Arquitetura - compasso e esquadro à mão, trajando roupas antigas e sentada sobre fragmentos de arquitetura clássica -, aponta para a cabana de madeira, como que a indicar a direção da boa Arquitetura. Entre os fragmentos e a cabana, a meio caminho, atrás da perna direita da figura feminina, nota-se parte de um fuste polido, ainda sem caneluras, como a indicar o aperfeiçoamento gradual pelo trabalho do homem, que se conclui com o fuste canelado do primeiro plano. Os fragmentos não parecem consistir em ruínas, pelo contrário, a impressão é de serem peças finalizadas, à espera da força humana, bem como dos princípios racionais que irão ordená-las - algo que parece caber à figura feminina, que assinala a fonte de tais princípios. O único fragmento que aparenta não estar destinado à construção é o trecho de pilastra, pois encontra-se parcialmente soterrado, e, como observado, consistia em artifício condenado por Laugier.
Tais metáforas sugeridas pela gravura de Eisen apontam para os pressupostos com os quais o sacerdote procurava confrontar as afetações do rococó e do barroco tardio, bem como as cópias dos modelos antigos produzidas pelos membros da Academia. Já Semper (1834, p.VII) tentava, com suas reflexões, fazer face à prática corrente dos arquitetos de seu tempo de produzir um "Walhalla à la Parthenon, uma basílica à la Monreale, um boudoir à la Pompeia, um palácio à la Pitti, uma igreja bizantina, ou mesmo um bazar ao gosto turco". Suas contendas dirigiam-se às expressões arquitetônicas oitocentistas e seus expedientes de imitação de materiais e cópias dos estilos do passado. A cabana caribenha com que ele se deparou na grande exposição londrina (conferir figura 4), como observado, não consiste em um padrão a seguir, no entanto, ela ilustra parte das reflexões de Semper.

De acordo com Mallgrave (1996), tratava-se de cabana exposta em escala real no stand expositivo das ilhas de Trinidad e Tobago. No Der Stil (1863, p.276) Semper chama a atenção do leitor para este exemplar, uma vez que era possível notar ali os motivos primordiais da Arquitetura em "seu modo mais puro e original": um pequeno local em cerâmica para o fogo, um telhado de bambu compondo unidade com os pilares que o sustentam, uma plataforma elevada e divisórias verticais de fibras trançadas, formando padrões decorativos e pendidas entre os suportes do telhado. No entendimento do autor, observar a condição originária, no sentido da 
consideração das técnicas primordiais e das características de cada material, assim como da compreensão do propósito e das forças simbólicas por trás de cada motivo, permitiria acompanhar e analisar o desenvolvimento dos motivos em obras posteriores. Além disso, esses fatores somados à atenção às particularidades externas em termos de geografia, clima, cultura, entre outras, poderiam auxiliar a evitar formas sem atenção ao propósito e carentes do sentido de adequação. Pode-se dizer que, sob a perspectiva semperiana, aí estaria a chave para o caminho da boa Arquitetura.

A leitura atenta das reflexões trazidas pelos dois autores mostra-se em grande medida oportuna, sobretudo tendo em vista momentos em que o horizonte da arquitetura se mostra incerto, sem leme ou direção. Tanto para Laugier quanto para Semper, a casa primordial era um recurso para tempos percebidos como de crise, e, em sua imagem estaria a chave para a relação entre passado e presente da Arquitetura.

\section{Referências}

ALBERTI, Leon Battista. Da arte de construir. Tratado de Arquitetura e Urbanismo. São Paulo: Hedra, 2012.

ANDRADE, Francisco Dias de. A imagem da cabana primitiva no Renascimento e a gênese da noção de arquitetura vernacular. Urbana, Campinas, vol.9, n.2, pp. 267-296, mai/ago 2017. Disponível em: https://periodicos.sbu.unicamp.br/ojs/index.php/urbana/article/view/8648611. Acesso em: 18.dez.2019.

AZEVEDO, Ricardo Marques de. Antigos modernos: estudo das doutrinas arquitetônicas nos séculos XVII e XVIII. São Paulo: Fauusp, 2009.

COLQUHOUN, Alan. Modernidade e tradição clássica: ensaios sobre arquitetura, 1980-1987. São Paulo: Cosac \& Naify, 2004.

GEORGIADIS, Sokratis. Sempers schwierige Rückkehr aus dem zweiten Exil. Werk, Bauen + Wohnen, Zürich, n.79, vol.4, pp. 61-62, 1992.

KAUFMANN, Emil. Three revolutionary architects, Boullée, Ledoux, and Lequeu. Transactions of the American Philosophical Society, Filadélfia, vol.42, p. 448, 1952. 
KLEMM, Gustav. Allgemeine Culturgeschichte der Menschheit. Leipzig: Teubner, 10 vol., 18431852.

LAUGIER, Marc-Antoine. Essai sur l'architecture Paris: chez Duchesne, 1755.

MALLGRAVE, Harry Francis. Gottfried Semper: architect of the nineteenth century. New Haven: Yale University Press, 1996.

MALLGRAVE, Harry Francis. Gustav Klemm and Gottfried Semper: the meeting of ethnological and architectural theory. RES: Anthropology and Aesthetics, New York, London, vol.9, pp. 6879,1985 .

MIDDLETON, Robin; WATKIN, David. Neoclassical and nineteenth century architecture. The Enlightenment in France and in England. London: Faber and Faber, 1987.

PEREIRA, Renata Baesso. Quatremère de Quincy e a ideia de tipo. RHAA, Campinas, n.13, pp. 5577, jan-jul. 2010.

RUMOHR, Karl Friedrich von. Italienische Forschungen. Berlin: Nicolai Verlag, vol 1, 1827.
RYKWERT, Joseph. A casa de Adão no paraíso: a ideia da cabana primitiva na história da arquitetura. São Paulo: Perspectiva, 2003.

RYKWERT, Joseph. A coluna dançante: sobre a ordem na arquitetura. São Paulo: Perspectiva, 2015.

SEMPER, Gottfried. Vorläufige Bemerkungen über bemalte Architectur und Plastik bei den Alten. Altona: Johann Friedrich Hammerich, 1834.

SEMPER, Gottfried. Die vier Elemente der Baukunst: ein Beitrag zur vergleichenden Baukunde. Braunschweig: Vieweg und Sohn, 1851.

SEMPER, Gottfried. Der Stil in den technischen und tektonischen Künsten, oder, Praktische Aesthetik. Ein Handbuch für Techniker, Künstler und Kunstfreunde. Frankfurt: Verlag für Kunst und Wissenschaft, vol.1, 1860.

SEMPER, Gottfried. Der Stil in den technischen und tektonischen Künsten, oder, Praktische Aesthetik. Ein Handbuch für Techniker, Künstler und Kunstfreunde. München: Friedrich Bruckmann 's Verlag, vol.2, 1863.

VÁZQUEZ RAMOS, Fernando G.; TOURINHO, Andréa de Oliveira. O Ensaio sobre a arquitetura, de Marc-Antoine Laugier: um tratado da simplicidade. 
Revista Arq.Urb, São Paulo, v.13, pp. 171-182, jan-jun. 2015. Disponível em: https://revistaarqurb.com.br/arqurb/article/view/276. Acesso em: 04.nov.2019.

VEN, Cornelis van de. Space in architecture: the evolution of a new idea in the theory and history of the modern movements. Assen: Van Gorcum, 1978.

VITRÚVIO. Tratado de Arquitetura. São Paulo: Martins Fontes, 2007.

WINCKELMANN, Johann Joachim. Historia del arte en la Antiguedad. Madrid: Ed. Aguilar, 1955. 